\title{
Variability of Upper Cervical Anatomy: A Reflection on Its Clinical Relevance
}

\author{
Erik Cattrysse $^{1, *}$, Luca Buzzatti ${ }^{1}$, Steven Provyn ${ }^{1,2}$, Marco Barbero ${ }^{3}$ and Peter Van Roy ${ }^{1}$ \\ 1 Arthrokinematics Research Group, Department of Physiotherapy, Human Physiology and Anatomy, \\ Vrije Universiteit Brussel, Brussels 1090, Belgium; luca.buzz@gmail.com (L.B.); \\ steven.provyn@vub.ac.be (S.P.); pvanroy@vub.ac.be (P.V.R.) \\ 2 Department of Anatomy, Morphology and Biomechanics, Haute École Paul Henri Spaak, \\ Brussels 1160, Belgium \\ 3 Rehabilitation Research Laboratory 2rLab, Department of Business Economics, Health and Social Care, \\ University of Applied Sciences and Arts of Southern Switzerland, SUPSI, 6928 Manno, Switzerland; \\ marco.barbero@supsi.ch \\ * Correspondence: ecattrys@vub.ac.be; Tel.:+32-2-477-4403; Fax: +32-2-477-4421
}

Academic Editor: Giuseppe Musumeci

Received: 21 October 2015; Accepted: 23 February 2016; Published: 9 March 2016

\begin{abstract}
The upper cervical complex is a distinctive spinal area with a great need for mobility as well as stability. The specific anatomical morphology of the atlanto-occipital and of the atlanto-axial joints seems to support these complex functional demands. The present study reports on some systematic and non-systematic observations of specific morphological variations and variants of the upper cervical joint anatomy. They are reported with respect to morphological features of the transverse atlantal and alar ligaments, morphological features of the lateral atlanto-axial and atlanto-occipital joints, additional joint configurations of the atlanto-occipital junction, muscular attachments to the joint capsule of the lateral atlanto occipital joint, and the Processus styloideus in its relationship with movements of the upper cervical joints. The observations mainly confirm general anatomical descriptions from textbooks, although some confront with these basic anatomical configurations mainly due to large morphological variation. Additionally, specific anatomical variants may raise questions on the generally accepted functional anatomical features. Some of these specific morphological configurations may have major implications for the kinematics of the occipito-atlanto-axial complex. This paper intends to reflect on the functional impact of the observed upper cervical morphological variability.
\end{abstract}

Keywords: upper-cervical; atlanto-axial; atlanto-occipital; morphology; anatomy; facet joints; ligaments

\section{Introduction}

Upper cervical stability is a major issue in current orthopedic medicine and spinal neurosurgery. Nevertheless, the concepts of stability and instability are an issue of discussion among clinicians as well as among biomechanical specialists [1]. Panjabi defined instability as "a significant decrease in the capacity of the stabilizing systems of the spine to maintain inter-vertebral neutral zones within physiological limits so that there is no major deformity, neurological deficit or incapacitating pain" [2]. This definition includes aspects of physiological as well as structural concepts of stability. As such, it refers to the interaction between passive, active and controlling functional systems. Anatomical features may contribute to passive and active aspects of stability. The morphological configuration of joints can be considered one of the main determinants of joint function.

The upper-cervical spine needs sufficient mobility to afford orientation in space as well as sufficient stability to support the head and protect the spinal cord. This combination has made it a very atypical 
spinal area. The lack of inter-vertebral disks can be considered a major example of this atypical spinal morphology.

Inter-individual morphological variation is one of the main challenges for anatomists. Although all medical courses are based on descriptive anatomy and rely on classical anatomical drawings from an extensive library of anatomical atlases, in general little attention is given to human anatomical variability. Clinicians will become aware of this anatomical variation during their professional career and will have to learn to deal with it in ad hoc clinical situations. Anatomical variants can be considered an extreme of anatomical variation. Anatomical variants began receiving increasing attention following systematic studies of morphology, starting with the "Varietates Berolinensis" and extended in basic works mainly from the 19th century [3-5]. More recent work, digital databases, and on-line facilities have made this knowledge more accessible [6,7]. Morphologic anomalies can be considered anatomical variations that may lead to impairment or loss of function.

The aim of the current study was to review the specific anatomical and morphological features of the upper cervical spine and to add to existing knowledge by documenting their anatomical variability. These observations may help clinicians to be aware of upper cervical morphological variability and help them in understanding how anatomy may contribute to functional demands concerning mobility as well as stability in this complex spinal area. The data are based on observations and digital recordings of 20 non-embalmed anatomical specimens and are discussed in the context of previously published data.

\section{Experimental Section}

Twenty fresh frozen cadaver specimens, 9 from male and 11 from female subjects (mean age $80 \pm 11$ years), were analyzed in order to study the specific morphology of the upper cervical ligaments and joints. Specimens were gathered from a body donation program (approved by the research commission of the Université René Descartes Paris 5, France, 2006).

The morphology was studied using a two-step 3D-digitizing technique to estimate absolute dimensions and relative orientations. During the first step, reference markers on the cranium, atlas, and axis were digitized using a 3D-microscribe-digitizer $\left({ }^{\circledR}\right.$ Immersion Corporation, San Jose, CA, USA). In a second step, the ligaments and joint capsules were dissected and the occiput, atlas, and axis were separated. Each anatomical segment was further analyzed, and a total of 96 anatomical references were digitized on the three segments. Finally, from the absolute data from step one and two, the relative coordinates of the anatomical landmarks were calculated by mathematical transformation of the dataset in order to create a 3D-reconstruction of all coordinates in a specimen-specific model. The methodology and results have been presented in detail elsewhere [8,9].

During the systematic dissection of 20 upper cervical spine specimens for the above-mentioned morphological study, additional observations were made of the specific anatomy of the area. These observations were documented and photographed.

\section{Results}

\subsection{Morphological Features of the Transverse Ligament of the Atlas and the Alar Ligaments}

The ligamentum transversum atlantis is an intrinsic ligament connecting two points on the same bony segment. In all specimens, the transverse ligament was inserted bilaterally on the tuberculum atlantis and ran transversally [8]. This is consistent with the literature [10]. This ligament divides the lumen of the atlas into two areas. The atlanto-odontoid joint is located anterior to the transverse ligament, while the medulla is situated posterior to it. The ligament had a mean length of $21.05 \mathrm{~mm}$ $( \pm 3 \mathrm{~mm})$ and a width of approximately $9 \mathrm{~mm}(9.2 \pm 2.2 \mathrm{~mm})$ (see Table 1) [8]. Considering the most dorsal aspect of the ligament relative to the areas of insertion, the ligament was positioned at a mean absolute angle of $119^{\circ}\left( \pm 17^{\circ}\right)$, but variation was observed from almost rectangular to nearly flat $[8,11]$ 
(Figure 1). No correlation was observed between the dimensions of the transverse ligament of the atlas and its angle.

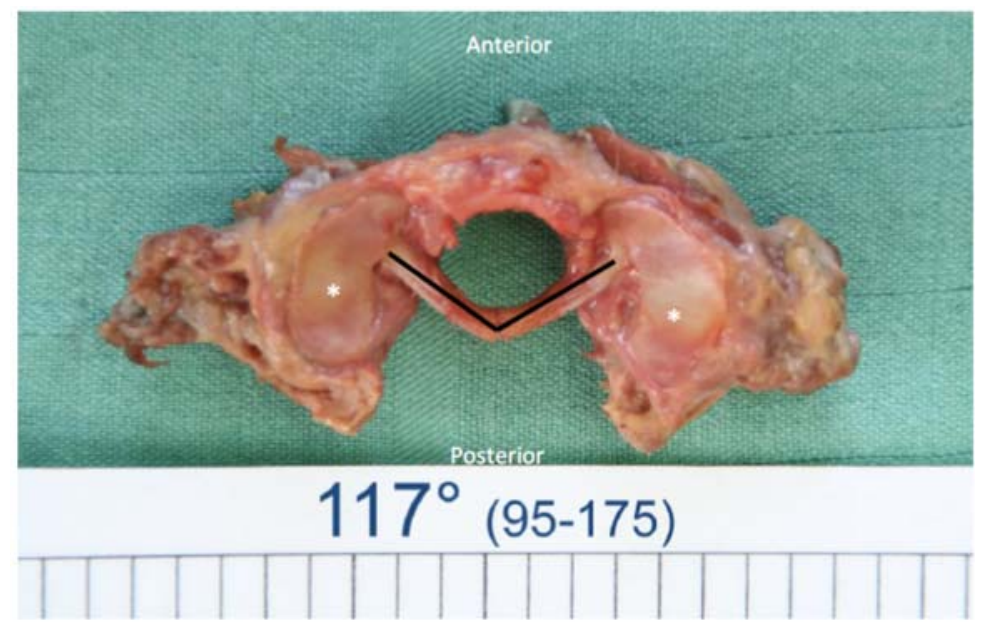

Figure 1. Angle of the transverse ligament of the atlas. Superior view on the atlas; the posterior arc has been removed; * indicates the superior articular facets of atlas.

In general the ligament wraps around the dens, fixing the dens to the anterior arch of the atlas [12]. Moreover, in many cases, the ligament is covered with hyaline cartilage on the anterior aspect, via which it becomes a functional part of the atlanto-odontoid joint. To some extent this configuration resembles that of the proximal radio-ulnar joint in which the radial annular ligament arches around the circumferentia radii, fixing the radial head to the ulna. Among the examined specimens several exhibited degeneration of the hyaline cartilage layer similar to age-related changes in other synovial joints.

The alar ligaments connect the cranial aspect of the dens to the occiput. In the analyzed specimens, all alar ligaments were attached to the medial side of the occipital condyles. Although many anatomical textbooks remain vague about the exact occipital insertion, this is consistent with the observations of other authors [12]. The overall length of the ligaments was $8.8 \mathrm{~mm}( \pm 2.6 \mathrm{~mm})$. The ligaments had a mean diameter of $7.3 \mathrm{~mm}( \pm 1.9 \mathrm{~mm})$, ranging from $2 \mathrm{~mm}$ to $10 \mathrm{~mm}$ (see Table 1). The mean absolute angle between the left and right alar ligaments was $117^{\circ}\left( \pm 31^{\circ}\right)$. There was no correlation between the length of the alar ligaments and their spatial orientation.

The ligaments, which consist predominantly of collagen fibers, are considered the main restraints in axial rotation mobility [13]. They are also considered the main determinants of the complex kinematics of motion coupling, with their orientation being the determining factor. Several authors have mentioned variability in alar ligament orientation [14], especially in the frontal plane ranging from craniolateral to caudolateral [15]; although a relationship with dens height has been suggested, this could not be demonstrated in more recent studies [16]. The plane of the alar ligaments showed a mean inclination of $-10^{\circ}$ with reference to the frontal plane of the axis, which indicates that it is predominantly inclined backward $[17,18]$. However, large deviations were present, varying from almost horizontally posterior inclined to almost horizontally anterior. In the present study, $60 \%$ of the specimens showed a backward inclination (Figure 2). Such variation should make clinicians careful in explaining and testing the integrity of the ligament by manual testing [19].

Some authors have described atlantal insertion of the alar ligaments [12,20]. However, like other authors, we were unable to confirm this. Nevertheless, in nearly all specimens, soft connective tissue was present between the dens and the anterolateral arch of the atlas without a well-delineated insertion area. This is consistent with earlier observations [21]. Some authors observed an additional connection that they describe as the anterior atlantodental ligament, which may help to prevent posterior displacement of the dens [22]. 


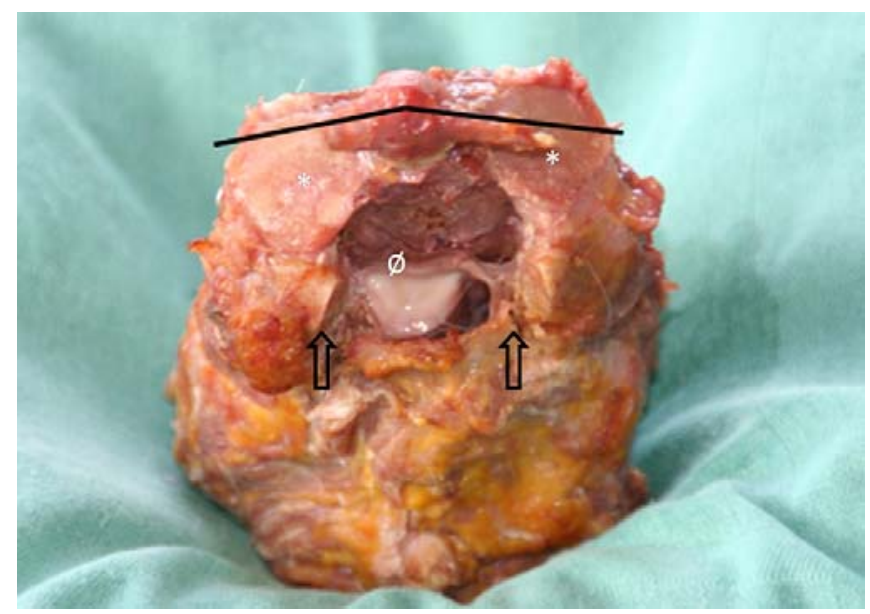

Figure 2. Backward inclination of the alar ligaments. Superior view on the axis (C2) and the cervical spine; laminae and spinous process of C2 have been removed; open arrows indicate section of laminae; * indicate superior joint facets of the axis; $\varnothing$ indicates spinal canal and medulla; black lines indicate orientation of the left and right alar ligament.

Table 1. Descriptive statistics of the alar and transverse ligaments.

\begin{tabular}{cccc}
\hline Alar Ligaments & $n$ & Mean & SD \\
\hline Sup-inf width on occ: left & 20 & 7.2 & 1.7 \\
Ant-post depth on occ: left & 20 & 8.4 & 2.6 \\
Sup-inf width on dens: left & 20 & 8.4 & 1.6 \\
Ant-post depth on dens: left & 20 & 5.9 & 1.5 \\
Sup-inf width on occ: right & 20 & 6.5 & 1.8 \\
Ant-post depth on occ: right & 20 & 7.9 & 2.4 \\
Sup-inf width on dens: right & 20 & 7.3 & 1.6 \\
Ant-post depth on dens: right & 20 & 5.8 & 1.6 \\
Length left & 18 & 8.8 & 2.6 \\
Length right & 17 & 8.9 & 2.6 \\
Absolute angle between left and right ligament & 18 & 117.2 & 31.0 \\
Angle to sagittal plane & 20 & 6.4 & 4.3 \\
Angle to frontal plane & 20 & -10.4 & 51.6 \\
\hline Transverse Ligaments & & & \\
\hline width & 19 & 9.2 & 2.2 \\
Absolute angle & 19 & 21.5 & 3.0 \\
\hline
\end{tabular}

Sup = superior; inf = inferior; ant = anterior, post = posterior; occ = occiput. SD: standard deviation.

Beside morphological variability, anatomical variation concerning the continuity between left and right alar ligaments was observed. These observations are consistent with the five types of configurations described in the literature [17]. Type I alar ligaments show fully separated insertions on the dens. Type II ligaments are partially connected, while type III ligaments show complete connection with coverage of the tip of the dens. Type IV is similar to the previous configuration but without coverage of the tip of the dens. Type V is a combination of III and I. A separate portion of the connecting superior fibers of the alar ligaments, similar to type IV, has been described and is considered an anatomical variant known as the transverse occipital ligament $[9,23]$. This was the case in one specimen in the present study (Figure 3). 


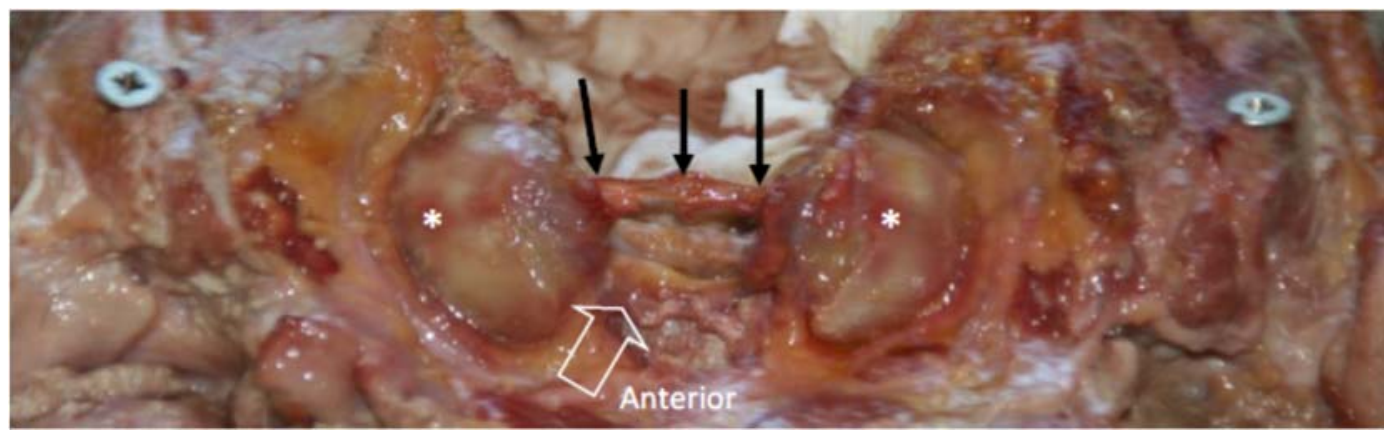

Figure 3. The transvers occipital ligament: Inferior view on the occiput, indicating the occipital condyles $\left({ }^{*}\right)$ and transverse occipital ligament (black arrows); the foramen magnum is indicated by the open arrow.

\subsection{Morphological Features of the Lateral Atlanto-Axial and Atlanto-Occipital Joints}

Cervical joint morphology shows important variability, while a narrow joint space approximating $1 \mathrm{~mm}$ seems to be one of the more stable observations [24].

In the present dataset, the mean diameter of the superior joint surface of the axis was somewhat larger than the mean diameter of the inferior joint surface of the atlas $(17.7 \pm 1.5 \mathrm{~mm} v \mathrm{~s}$. $16.8 \pm 1.7 \mathrm{~mm}$ ) [8,25-29]. No significant differences were observed between the anterior to posterior diameter and the medial to lateral diameter of the joint surfaces, and the facets were almost round (Figure 4). The surface area was calculated approximating the facet joint to a half ellipsoid. Using Knud Thomsen's Formula $\left(\mathrm{S} \approx 4 \pi\left[\left(a^{\mathrm{P}} b^{\mathrm{P}}+a^{\mathrm{P}} c^{\mathrm{P}}+b^{\mathrm{P}} c^{\mathrm{P}}\right) / 3\right]^{1 / \mathrm{p}}\right)$ with $p \approx 1.6075$, it was possible to recalculate the area of the facet joints while also taking their depth into account. With this approach, the mean surface of the inferior left facet of the atlas was $215.3 \pm 34.1 \mathrm{~mm}^{2}$, while the right facet was $212.8 \pm 37.7 \mathrm{~mm}^{2}$. The surface of the superior left facet of the axis was $239.4 \pm 39.8 \mathrm{~mm}^{2}$, and the right facet was $240.9 \pm 43.1 \mathrm{~mm}^{2}$. Statistically speaking, these values are significantly different from previous calculations [9].

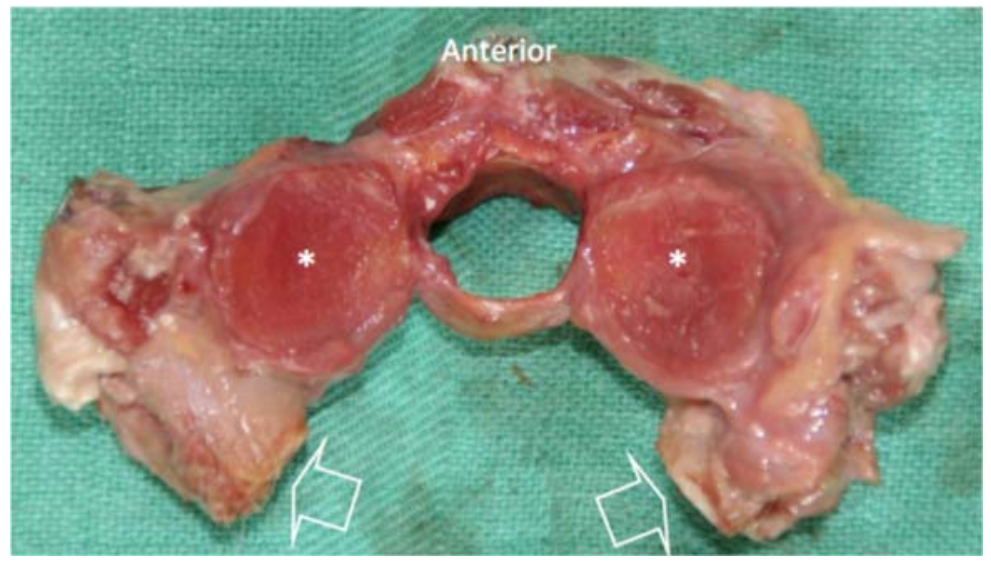

Figure 4. Nearly round configuration of the inferior facets of the atlas (indicated by *). Inferior view on the atlas; the posterior arc has been removed (sections are indicated by open arrows).

A biconvex configuration of the lateral atlanto-axial joints as described in the literature $[20,29,30]$ could not be demonstrated in the present dataset. The mean heights of the joint surfaces of the atlas and the axis were very small $(0-3 \mathrm{~mm})$ (see Table 2$)$. This resulted in very small height-to-diameter ratios. Higher ratios between surface diameter and surface height reflect more curved joint surfaces. In this set of older aged specimens, the ratios varied from slightly negative to slightly positive values ( -0.11 to 0.13$)$, indicating variation from a slight concavity of the surface area to a slight convexity [9]. 
The absolute angles between the left and right superior facet joints of the axis and inferior facet joints of the atlas were comparable (mean values $132.0^{\circ}$ vs. $130.0^{\circ}$ ). The relative angles of the joint surfaces of the axis and atlas with reference to the sagittal and frontal planes of the axis had a mean value of $22.2^{\circ}$ for the inferior joint surfaces of the atlas and $24.0^{\circ}$ for the superior joint surfaces of the axis. Large standard deviations in the values for the angles to the frontal planes indicated that variation between specimens was extensive [9]. Nevertheless, the orientation of the joint surfaces with respect to the sagittal plane of the axis demonstrated good congruency between the axis and atlas (see Table 2).

The atlanto-occipital joint represents the most explicit convex-concave joint configuration in the spine [27]. The height of the occipital condyles varied from 0 to $5 \mathrm{~mm}$, with the mean ratio between height and anterior to posterior diameter being 0.12 (range 0.09 to 0.20 ). Accordingly, the depth of the superior joint surfaces of the atlas varied from 0 to $4.7 \mathrm{~mm}$, and the mean ratio was 0.12 (range -0.06 to 0.20 ). The joint facets on the occipital condyles and atlas facets were slightly more curved in the medial-lateral direction with respective mean ratios of 0.18 on the condyles (range 0 to 0.40 ) and 0.16 on the atlas facets (range -0.3 to 0.29 ) (Figure 5).
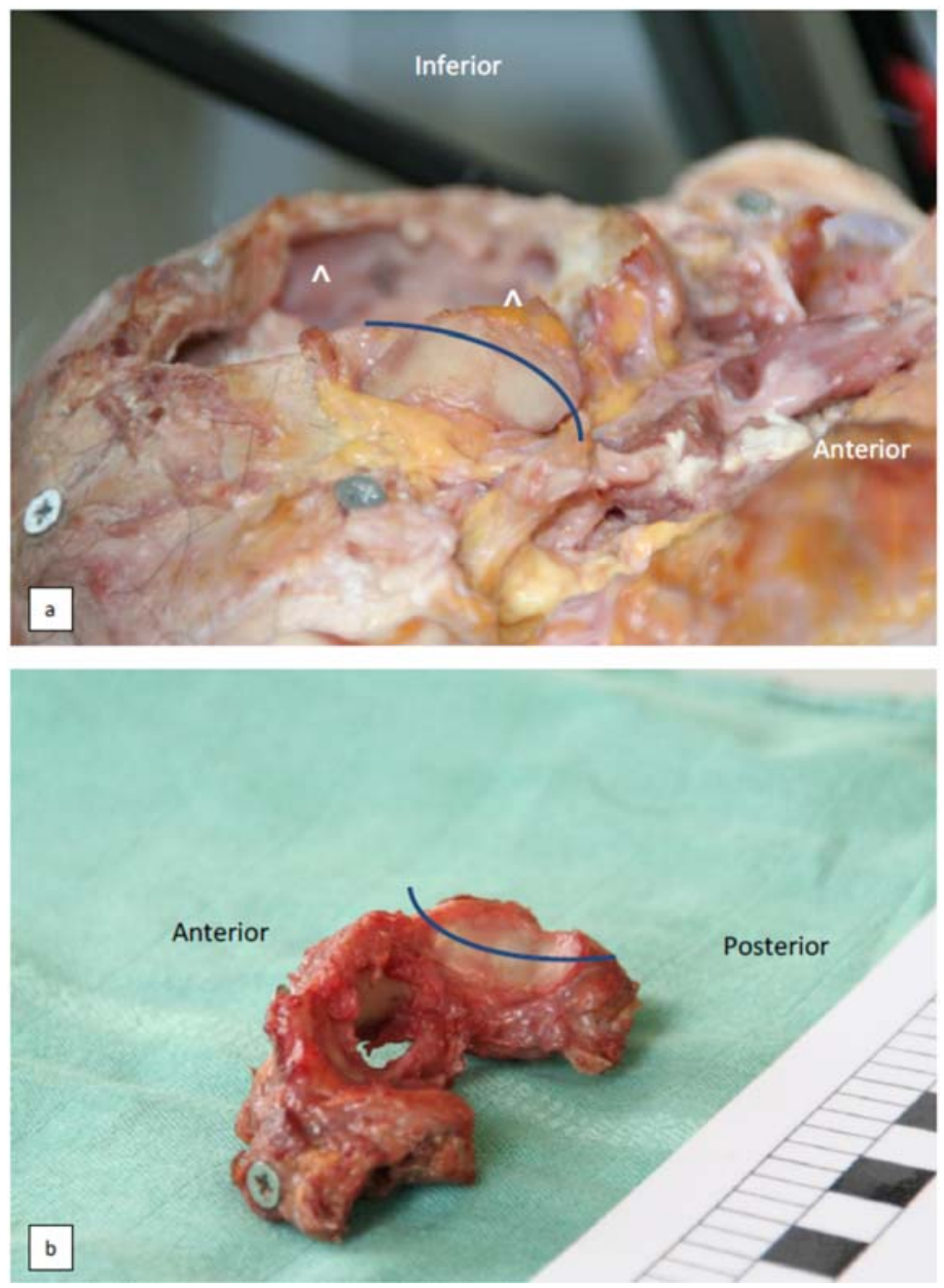

Figure 5. (a) Convex curvature of the occipital condyles (arrow points indicate foramen magnum); (b) Associated concavity on the superior facets of the atlas (posterior arc has been removed; transverse atlantal ligament is intact). Blue lines demonstrate the curvature of the articular surface

A study by Hallgren et al. described the differences between the orientation of the anterior and posterior aspects of the atlantal facets [31], with the angulation between the two parts of the joint 
surface expressing the anterior to posterior curvature. The anterior to posterior curvature of the superior joint facet surfaces of the atlas increases from an average angle of $11.5^{\circ}\left(+/-4.7^{\circ}\right)$ at 1 year of age and asymptotically approaches an average angle of $43.5^{\circ}\left(+/-13.4^{\circ}\right)$ at 80 years of age. There is a direct relationship between age and the anterior to posterior curvature of the superior joint surfaces of the atlas that can be approximated $\left(r^{2}=0.94\right)$ with a sigmoid function. Ninety percent of the final curvature is achieved at approximately 8 years of age.

Table 2. Dimensions and orientation of the superior joint facets of the axis and the inferior facets of the atlas.

\begin{tabular}{ccccc}
\hline $\boldsymbol{n}=\mathbf{2 0}$ & \multicolumn{2}{c}{ Left } & Right \\
\hline Absolute dimensions & mean & SD & mean & SD \\
\hline Axis superior mean diameter & 17.7 & 1.4 & 17.7 & 1.7 \\
Axis superior surface area & 234.5 & 38.6 & 235.2 & 41.0 \\
Atlas inferior mean diameter & 17.0 & 1.4 & 17.0 & 1.5 \\
Atlas inferior surface area & 213.0 & 33.8 & 210.5 & 37.0 \\
Axis height & 0.2 & 1.2 & 0.3 & 1.1 \\
Axis ratio & 0.01 & 0.07 & 0.02 & 0.07 \\
Atlas height & 0.0 & 0.4 & 0.1 & 0.3 \\
Atlas ratio & 0.00 & 0.02 & 0.00 & 0.04 \\
\hline Relative angles & & & & \\
\hline Atlas & mean & SD & mean & SD \\
\hline Angle to sagittal plane & 21.3 & 6.0 & -23.2 & 5.9 \\
Angle to frontal plane & -8.9 & 59.5 & 15.2 & 48.9 \\
\hline Axis & mean & SD & mean & SD \\
\hline Angle to sagittal plane & 23.3 & 5.1 & -24.7 & 5.7 \\
Angle to frontal plane & -9.6 & 52.2 & 0.3 & 57.8 \\
\hline
\end{tabular}

Diameters and heights are in $\mathrm{mm}$, areas in $\mathrm{mm}^{2}$, angles in degrees; ratio = height/diameter; $\mathrm{SD}=$ standard deviation.

\subsection{Additional Joint Configurations of the Atlanto-Occipital Junction}

An additional joint between the dens axis and the occiput was present in one of the subjects (Figure 6A,B) known as a third or median occipital condyle configuration [32,33]. It consisted of a synovial-like articulation with a distinctive concave joint surface on the occiput and a convex surface on the dens. The joint surface on the occiput was located anteriorly and centrally between the two occipital condyles on the edge of the foramen magnum. This accessory odonto-occipital joint had a hyaline cartilage layer that was concave in both the anterior to posterior as well as the medial to lateral direction. It was slightly oriented in the frontal plane. This was consistent with the orientation of the odontoid joint surface, which was located on the anterosuperior part of the dens. There was no clear cartilage layer on this joint surface, which might be due to degenerative changes (wear, irregularity, calcification or absence) related to the age of the specimens.

One other type variant of a third occipital condyle [33] was observed in one specimen with an additional bone connection between atlas and occiput (Figure 7A,B). In this specimen, a rough bony articular connection was located between the superior aspect of the anterior arch of the atlas and the inferior aspect of the anterior edge of the foramen magnum. None of the two articulating surfaces showed any cartilage in this older aged specimen, and no joint capsule could be recognized. Additionally, the normal synovial lateral atlanto-occipital joints demonstrated a strange configuration with a lack of congruity between joint curvatures. The oval-shaped joint surfaces were relatively flat to concave in the occipital part and normally concave in the atlantal part.

In one case, a clear consolidation of atlas and occiput was observed due to bony bridging of the left lateral atlanto-occipital joint (Figure 8). This was confirmed by a lack of mobility in any direction at 
the atlanto-occipital level. Such occipitalization may include other soft tissue changes in suboccipital muscles and the passage of the vertebral artery in the atlanto-occipital segment [34].
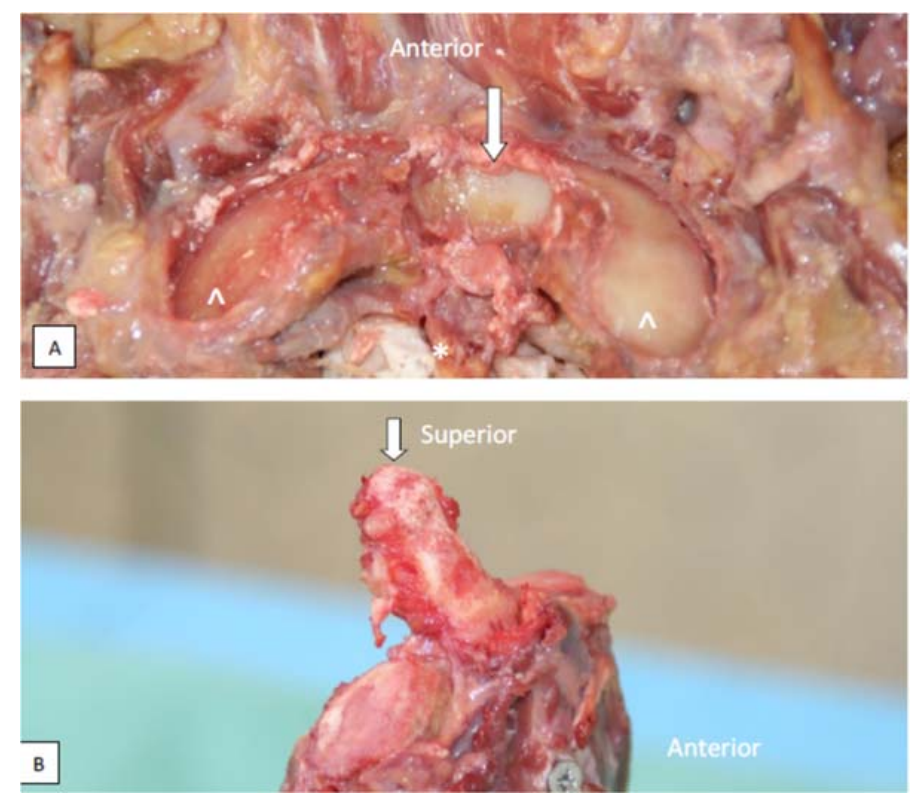

Figure 6. Additional joint between the dens axis and the occiput (arrow) (A) Joint facet at the anterior rim of the foramen magnum $\left({ }^{*}\right)$ in between the occipital condyles ( $\left(^{\wedge}\right)$; (B) Joint facet on the top of the dens (arrow).

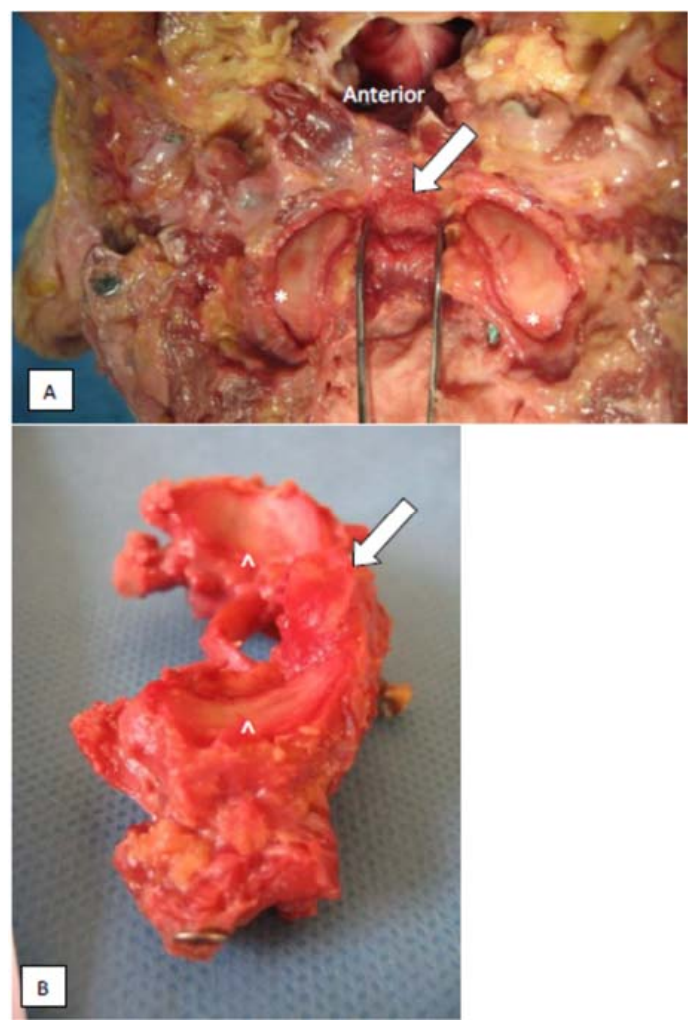

Figure 7. Additional atlanto-occipital bone connection due to third occipital condyle configuration. (A) Joint facet on the anterior rim of the foramen magnum (arrow); * indicate occipital condyles; (B) Additional joint facet at superior aspect of the anterior arch of the atlas (arrow); the posterior arc of the atlas has been removed; ${ }^{\wedge}$ indicate superior joint facets of the atlas. 


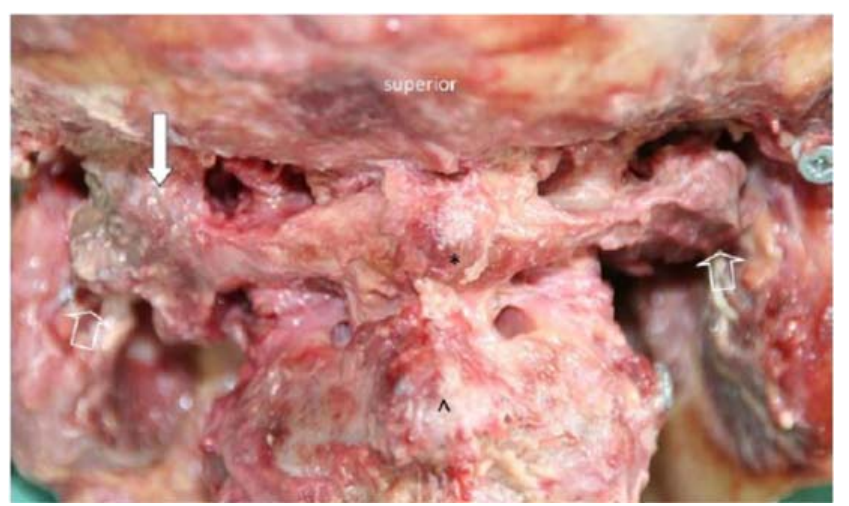

Figure 8. Bony bridging between left transverse process and occiput, resulting in full absence of mobility; * posterior tubercle of the atlas; ^ spinous process of C2; Open arrow: transverse processes of C2; White arrow: bony bridge.

\subsection{Muscular Attachments to the Joint Capsule of the Lateral Atlanto-Occipital Joint}

During dissection several non-systematic observations were made of muscular attachments to the lateral atlanto-axial joints. Mainly fibers of the superior oblique and longitudinal part of the M. longus colli attached to the anterior aspect of the joint capsule (Figure 9). These fibers had a cranio-caudal orientation and were directly inserted on the $\mathrm{C} 1-\mathrm{C} 2$ joint capsule.
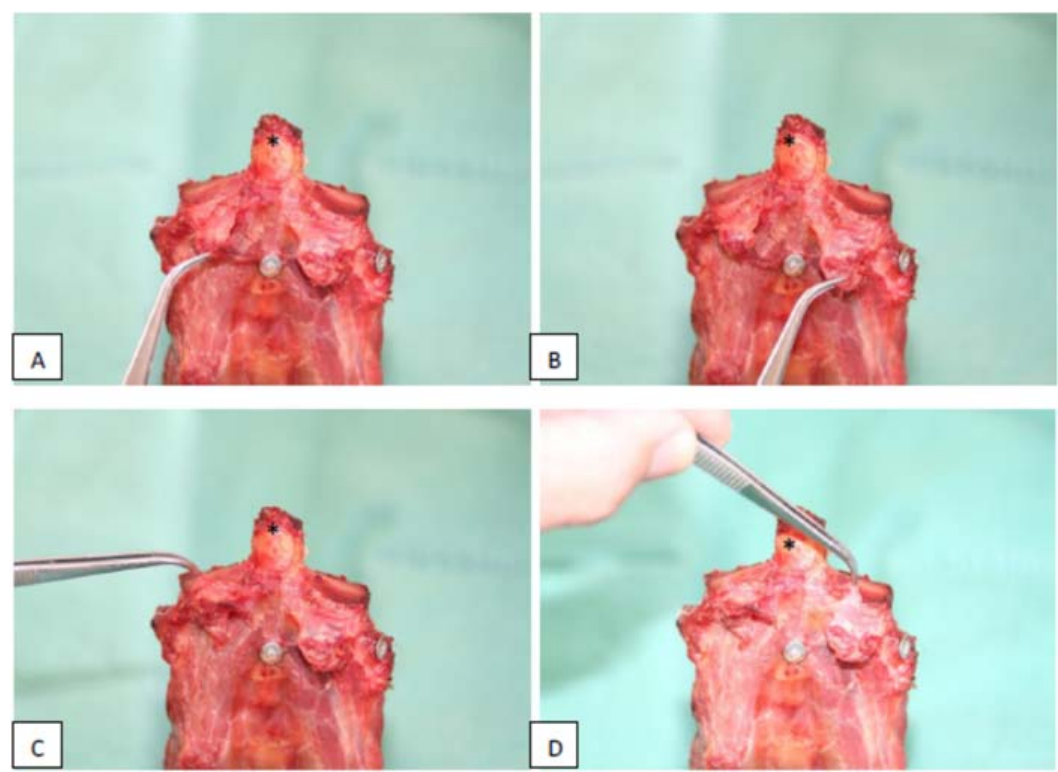

Figure 9. Attachment of the longus colli muscle to the atlanto-axial zygapophysial joint capsules. Anterior view on the axis and inferior cervical spine; * indicates the dens pincer indicates right (A) and left (B) muscular cut of the longus colli retracted inferiorly and right (C) and left (D) joint capsule of the atlanto-axial lateral joints.

\subsection{The processus Styloideus and Its Relationship with Movements of the Upper Cervical Joints}

In cases with a prolonged styloid process, the transverse process of $\mathrm{C} 1$ approaches the styloid in a flexed head position (Figure 10). As a result, no further segmental movement between the occiput and atlas could be observed in a flexed position (Figure 11). In contrast, complex combined 3D movements were possible during axial rotation in an extended position. This may be of great relevance for clinicians when evaluating or treating mobility disorders of the upper cervical spine. Forced rotation in flexion may harm the osseus and vulnerable tissue laying in between. 


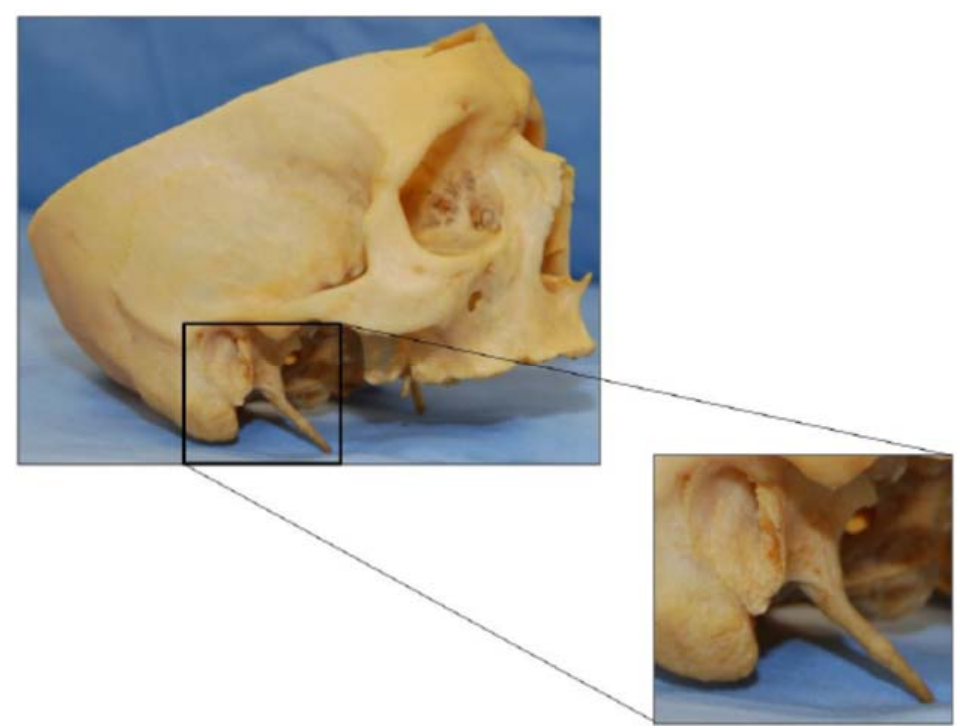

Figure 10. Prolonged processus styloideus.
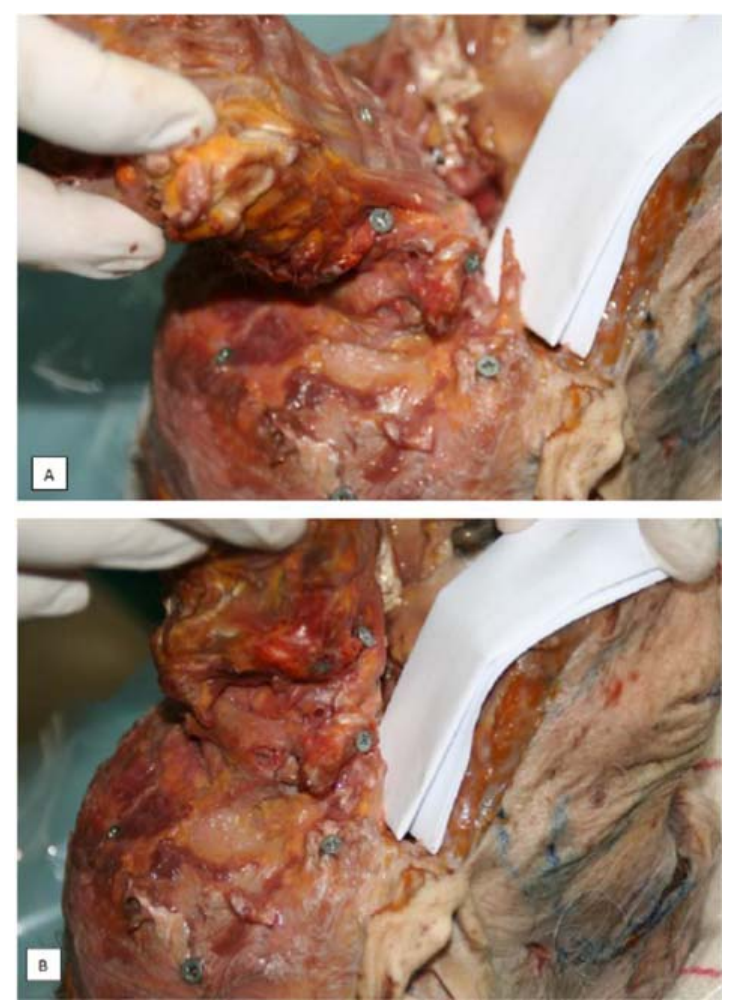

Figure 11. Approximation of the transverse process of the atlas and processus styloideus in a flexed upper cervical spine position. (A) Extension position; (B) Flexion position.

\section{Discussion}

The above-described systematic and occasional non-systematic observations of anatomical variability and variants of the upper cervical joint configuration support existing concepts suggesting a need for mobility as well as stability in the upper cervical spine.

Congruency between relative joint surfaces could not be demonstrated in the current sample. The relationship between the anterior to posterior length of the articular joint surfaces as well as between the medial to lateral width relative to the depth/height showed intra class correlations 
below 0.6 for superior and inferior joint surfaces. Others have observed a similar lack of congruency between superior and inferior atlanto-occipital joint surfaces [35], although a clear relationship could be demonstrated in the atlanto-axial facet joint areas with slightly larger surface areas for the superior axial compared to the inferior atlantal articular areas [9].

Although some connective tissue, probably relating to the atlas-dens connection, was present, no atlantal part of the alar ligaments was observed in this study. It is, however, questionable that the observed connective tissue in the present study, lacking a dens fiber organization, would be able to induce sufficient strain to have a direct impact on the kinematics and especially on the stability of the occipito-atlanto-axial joint complex. Others have demonstrated the possible presence of an anterior small but firm atlanto-dental ligament that may support anterior to posterior stability [22].

It has been suggested that the relatively flat joint configuration between head and spine in children may be related to instability, an increased vulnerability for Whiplash Associated Disorders and a predisposition for the Shaken Baby Syndrome [36]. In adults, the atlanto-occipital joint is considered the most convex-concave joint configuration in the spine [27]. A study by Hallgren described the differences between the orientation of the anterior and posterior aspects of the atlantal facets [31]. The anterior to posterior curvature predisposes for mobility in the flexion-extension direction [36-40]. Whether any mobility in the frontal and transverse planes may occur in the atlanto-occipital joints remains a questionable issue [41]. Motion components in the frontal and transverse planes are generally considered to be negligible and less than 5 degrees for the overall range of motion [42-44]. However, some authors have reported motion components in these planes exceeding $10^{\circ}$ depending on the starting position and with a tendency to slightly larger ranges derived from in vitro studies [20,31]. It can be argued that the combined atlanto-axial joints can be considered as parts of an irregular ball and socket joint, which will allow a certain amount of axial rotation. However, if the anterior to posterior curvature is higher, or if the anterior facets of the joints are more oriented in the frontal plane and more curved in shape, the resulting configuration should be regarded as part of an ellipsoid joint capable of no or only slight axial rotation [45,46]. This morphological variability may explain some of the variation in the reported ranges of motion [36].

A biconvex configuration of the lateral atlanto-axial joints has been reported in the literature $[20,29,30]$. The inferior bony joint surface of the atlas is generally flat, whereas the superior aspect of the joint surface of the axis is generally convex in the anterior-posterior direction. However, the anterior to posterior convexity of both lateral joint surfaces can partially be attributed to the joint cartilage and may disappear as a result of degeneration [31]. As such, it can be considered normal that biconvexity could not be demonstrated in the present dataset based on older aged cadaver material.

Muscular attachment of the longus colli muscle to the atlanto-axial joint capsule may help stabilize the joint in a mechanical as well as in a neuromuscular way. As the fibers run longitudinally along the spine, close to the center of the joint, the muscular lever arm is very short and the torque produced will mainly exert a compressive effect in the joint. Given their attachment, they may also function as a tensor of the very lax joint capsule.

As demonstrated in several studies, the contact area between atlanto-axial joint surfaces during full rotational position may be as low as $15 \%$ in children [47] and $30 \%$ in adults [37]. The distances between the edges of the superior and inferior surfaces show mean values of $7.6 \mathrm{~mm}( \pm 0.8 \mathrm{~mm})$ during full active axial rotation in adults [48]. Displacement of the inferior facet of the atlas relative to the superior facet of the axis has also been reported during manual techniques. The displacement induced with a combined motion technique (High Velocity Low Amplitude thrust into rotation) shows a mean value of $5.6 \mathrm{~mm}( \pm 2.9)$ if the whole movement from the neutral position to the end of the maneuver is taken into account. A mean displacement of $0.5 \mathrm{~mm}( \pm 0.5)$ was reported considering only the impulse phase [49]. Compering these values with those from active rotation of the head [46,47,50], it is possible to assume that the inter-vertebral movement induced with such combined motion technique is not able to endanger vital structures such as the vertebral arteries and the spinal cord. 
Innervation of the anterior part of the joint capsule has been demonstrated, rising from the ventral plexus of C2 [51]. This supports the rationale that the muscle may exert a proprioceptive function, enhancing the stabilization and control of movement in the atlanto-occipital joint.

It is well-known that a prolonged processus styloideus may cause complaints in the head and neck region. This situation has been described as Eagle's syndrome since 1937 [52], although it had already been recognized in 1652 as the stylo-carotidic or prolonged processus styloid syndrome by Marchetti. Based on observations of a prolonged styloid process and its impact during axial rotation, it is common sense to avoid forced upper cervical motion in the flexed position in the elderly, especially in cases with long styloid processes. Forceful rotation or forced flexion may compress neurovascular structures such as the arteria carotis interna and externa, vena jugularis interna, accessory, glosso pharyngeal, and vagus nerves, located in the area of the styloid process. Such movements may even cause fracture of the styloid.

\section{Conclusions}

This study on the anatomical features of the upper cervical spine support the function of mobility (e.g., relatively flat joint surfaces at the atlanto-axial joint allowing large ranges of motion) as well as stability (muscular attachments to the joint capsules of the atlanto-axial joints) in the atlanto-axial as well as in the atlanto-occipital joints (pronounced anterior to posterior convexity), allowing motion in the sagittal plane, although variable joint facet angulations may restrict motion in specific directions and could be influenced by specific ligament configurations.

Although morphology does not seem to influence motion coupling behavior in the atlanto-axial joint during passive rotatory mobilization [53], the specific impact of upper cervical morphological variation on segmental kinematics has not yet been documented in relation to daily life activities and clinical situations. Nevertheless, clinicians should take this variability into consideration when planning their interventions.

Acknowledgments: The authors thank the Anatomy Department of the Université Rene' Descartes-Paris 5 in France for providing the opportunity to perform this study on fresh cadaver specimens.

Author Contributions: All authors participated actively in data gathering (Erik Cattrysse, Steven Provyn, Marco Barbero), data analysis (Erik Cattrysse, Luca Buzzatti) and writing (Erik Cattrysse, Luca Buzzatti) and reviewing (Erik Cattrysse, Luca Buzzatti, Steven Provyn, Marco Barbero and Peter Van Roy).

Conflicts of Interest: The authors declare no conflict of interest.

\section{References}

1. Reeves, N.P.; Narendra, K.S.; Cholewicki, J. Spine stability: The six blind man and the elephant. Clin. Biomech. 2007, 22, 266-274. [CrossRef] [PubMed]

2. Panjabi, M.M. The stabilizing system of the spine .1. Function, dysfunction, adaptation, and enhancement. J. Spinal Disord. 1992, 5, 383-389. [CrossRef] [PubMed]

3. Testut, L. Les Anomalies Musculaires chez l'Homme, Expliquées par Lanatomie Comparée; G. Masson: Paris, France, 1884.

4. Le Double, A.F. Traité des Variations Musculaires et Leur Significations au Point de Vue de l'Anthropologie Zoologique; Schleicher-Frères: Paris, France, 1897.

5. Krause, W. Anatomische Varietäten; Hahn'sche Buchhandlung: Hannover, Germany, 1880.

6. Bergman, R.A.; Afifi, A.K. Illustrated Encyclopedia of Human Anatomic Variation; The University of Iowa: Iowa City, IA, USA, 1996.

7. Bergman, R.A.; Thompson, S.A.; Afifi, A.K.; Saadeh, F.A. Compendium of Human Anatomic Variation; Urban and Schwarzenberg: Baltimore, MD, USA, 1988.

8. Cattrysse, E.; Barbero, M.; Gagey, O.; Kool, P.; Clarys, J.P.; Van Roy, P. 3D morphometry of the transverse and alar ligaments in the occipito-atlanto-axial spine: An in vitro analysis. Clin. Anat. 2007, 20, 892-899. [CrossRef] [PubMed]

9. Cattrysse, E.; Gagey, O.; Clarys, J.P.; Van Roy, P. In vitro 3-dimensional morphometry of the lateral atlanto-axial articular surfaces. Spine 2008, 33, 1503-1508. [CrossRef] [PubMed] 
10. Tubbs, R.S.; Wellons, J.C., 3rd; Banks, J.; Blount, J.P.; Oakes, W.J. Quantitative anatomy of the transverse ligament tubercles. J. Neurosurg. 2002, 97, 343-345. [PubMed]

11. Burguet, J.L.; Sick, H.; Dirheimer, Y.; Wackenheim, A. CT of the main ligaments of the cervico-occipital hinge. Neuroradiology 1985, 27, 112-118. [CrossRef] [PubMed]

12. Krakenes, J.; Kaale, B.R.; Rorvik, J.; Gilhus, N.E. Mri assessment of normal ligamentous structures in the craniovertebral junction. Neuroradiology 2001, 43, 1089-1097. [CrossRef] [PubMed]

13. Saldinger, P.; Dvorak, J.; Rahn, B.A.; Perren, S.M. Histology of the alar and transverse ligaments. Spine 1990, 15, 257-261. [CrossRef] [PubMed]

14. Schmidt, P.; Mayer, T.E.; Drescher, R. Delineation of alar ligament morphology: Comparison of magnetic resonance imaging at 1.5 and 3 tesla. Orthopedics 2012, 35, E1635-E1639. [CrossRef] [PubMed]

15. Lummel, N.; Zeif, C.; Kloetzer, A.; Linn, J.; Bruckmann, H.; Bitterling, H. Variability of morphology and signal intensity of alar ligaments in healthy volunteers using $\mathrm{mr}$ imaging. Am. J. Neuroradiol. 2011, 32, 125-130. [CrossRef] [PubMed]

16. Osmotherly, P.G.; Rawson, O.A.; Rowe, L.J. The relationship between dens height and alar ligament orientation: A radiologic study. J. Manip. Physiol. Ther. 2011, 34, 181-187. [CrossRef] [PubMed]

17. Dvorak, J.; Panjabi, M.M. Functional-anatomy of the alar ligaments. Spine 1987, 12, 183-189. [CrossRef] [PubMed]

18. Dvorak, J.; Penning, L.; Hayek, J.; Panjabi, M.M.; Grob, D.; Zehnder, R. Functional diagnostics of the cervical spine using computer-tomography. Neuroradiology 1988, 30, 132-137. [CrossRef] [PubMed]

19. Osmotherly, P.G.; Rivett, D.A.; Mercer, S.R. Revisiting the clinical anatomy of the alar ligaments. Eur. Spine J. 2013, 22, 60-64. [CrossRef] [PubMed]

20. Van Roy, P.; Barbaix, E.; Clarys, J.P. Functional anatomy of the cervical spine. In The Degenerative Cervical Spine; Spalski, M., Gunzburg, R., Eds.; Lippincott Williams \& Wilkins: Philadelphia, PA, USA, 2001; pp. 3-27.

21. Okazaki, K. Anatomical study of the ligaments in the occipito-atlantoaxial complex. Nippon Seikeigeka Gakkai Zasshi 1995, 69, 1259-1267. [PubMed]

22. Tubbs, R.S.; Mortazavi, M.M.; Louis, R.G.; Loukas, M.; Shoja, M.M.; Chern, J.J.; Benninger, B.; Cohen-Gadol, A.A. The anterior atlantodental ligament: Its anatomy and potential functional significance. World Neurosurg. 2012, 77, 775-777. [CrossRef] [PubMed]

23. Lenz, R.; Moore, G.D.; Panchani, P.N.; DiLandro, A.C.; Battaglia, F.; Tubbs, R.S.; Shoja, M.M.; Loukas, M.; Kozlowski, P.B.; D'Antoni, A.V. The transverse occipital ligament: An anatomic, histologic, and radiographic study. Spine J. 2012, 12, 596-602. [CrossRef] [PubMed]

24. Radcliff, K.E.; Ben-Galim, P.; Dreiangel, N.; Martin, S.B.; Reitman, C.A.; Lin, J.N.; Hipp, J.A. Comprehensive computed tomography assessment of the upper cervical anatomy: What is normal? Spine J. 2010, 10, $219-229$. [CrossRef] [PubMed]

25. Rauschning, W. Detailed sectional anatomy of the spine. In Multiplanar CT of the Spine; Rothman, S., Glenn, W.V., Eds.; University Park Press: Baltimore, MD, USA, 1985; pp. 33-35.

26. Rauschning, W. Anatomy and pathology of the cervical spine. In The Adult Spine: Principles and Practice; Frymoyer, J.W., Ed.; Raven Press: New York, NY, USA, 1991; pp. 907-928.

27. Rauschning, W.; Bergstrom, K.; Pech, P. Correlative craniospinal anatomy by computed-tomography and cryomicrotomy. J. Comput. Assist. Tomogr. 1983, 7, 9-13. [CrossRef] [PubMed]

28. Rauschning, W.; Glenn, W.V. Atlas of Sectional Anatomy: Head, Neck and Thrunk. N. Engl. J. Med. 1984, 311, 267-268. [CrossRef]

29. Rothman, S.; Glenn, W.V. Multiplanar CT of the Spine; University Park Press: Baltimore, MD, USA, 1985.

30. Konig, S.A.; Goldammer, A.; Vitzthum, H.E. Anatomical data on the craniocervical junction and their correlation with degenerative changes in 30 cadaveric specimens. J. Neurosurg. Spine 2005, 3, 379-385. [CrossRef] [PubMed]

31. Hallgren, R.C.; Cattrysse, E.; Zrull, J.M. In vitro characterization of the anterior to posterior curvature of the superior articular facets of the atlas as a function of age. Spine J. 2011, 11, 241-244. [CrossRef] [PubMed]

32. Lofrese, G.; De Iure, F.; Cappuccio, M.; Amendola, L. Occipital condyles congenital dislocation and condylus tertius an unstable association revealing a new abnormality of the craniocervical junction. Spine 2015, 40, E992-E995. [CrossRef] [PubMed]

33. Udare, A.S.; Bansal, D.; Patel, B.; Mondel, P.K.; Aiyer, S. Condylus tertius with atlanto-axial rotatory fixation: An unreported association. Skelet. Radiol. 2014, 43, 535-539. [CrossRef] [PubMed] 
34. Bodon, G.; Glasz, T.; Olerud, C. Anatomical changes in occipitalization: Is there an increased risk during the standard posterior approach? Eur. Spine J. 2013, 22, S512-S516. [CrossRef] [PubMed]

35. Briggs, L.; Hart, J.; Navis, M.; Clayton, S.; Boone, R. Surface area congruence of atlas superior articulating facets and occipital condyles. J. Chiropr. Med. 2008, 7, 9-16. [CrossRef] [PubMed]

36. Bogduk, N.; Mercer, S. Biomechanics of the cervical spine. I: Normal kinematics. Clin. Biomech. 2000, 15, 633-648. [CrossRef]

37. Ishii, T.; Mukai, Y.; Hosono, N.; Sakaura, H.; Fujii, R.; Nakajima, Y.; Tamura, S.; Iwasaki, M.; Yoshikawa, H.; Sugamoto, K. Kinematics of the cervical spine in lateral bending in vivo three-dimensional analysis. Spine 2006, 31, 155-160. [CrossRef] [PubMed]

38. Ishii, T.; Mukai, Y.; Hosono, N.; Sakaura, H.; Nakajima, Y.; Sato, Y.; Sugamoto, K.; Yoshikawa, H. Kinematics of the upper cervical spine in rotation-In vivo three-dimensional analysis. Spine 2004, 29, E139-E144. [CrossRef] [PubMed]

39. Pfirrmann, C.W.A.; Binkert, C.A.; Zanetti, M.; Boos, N.; Hodler, J. Functional MR imaging of the craniocervical junction. Correlation with alar ligaments and occipito-atlantoaxial joint morphology: A study in 50 asymptomatic subjects. Schweiz. Med. Wochenschr. 2000, 130, 645-651. [PubMed]

40. Cattrysse, E.; Baeyens, J.P.; Clarys, J.P.; Van Roy, P. Three dimensional kinematics of manual upper cervical mobilization: Part 2: An in vitro analysis of manual axial rotation and lateral bending mobilization of the atlanto-axial joint. Man. Ther. 2007, 12, 353-362. [CrossRef] [PubMed]

41. Liu, K.; Niu, X.C.; Wu, C.Y.; Guo, L.F.; Liu, C.; Song, H.X.; Chhabra, A. Normative data on axial rotation of atlanto-occipital joint on 3 tesla MRI using a simple and reliable method of calculation. Acta Radiol. 2013, 54, 1175-1181. [CrossRef] [PubMed]

42. Panjabi, M.M.; Oda, T.; Crisco, J.J.; Dvorak, J.; Grob, D. Posture affects motion coupling patterns of the upper cervical spine. J. Orthop. Res. 1993, 11, 525-536. [CrossRef] [PubMed]

43. Dvorak, J.; Panjabi, M.; Gerber, M.; Wichmann, W. CT-functional diagnostics of the rotatory instability of upper cervical spine.1. An experimental-study on cadavers. Spine 1987, 12, 197-205. [CrossRef] [PubMed]

44. Panjabi, M.M.; Miura, T.; Cripton, P.A.; Wang, J.L.; Nain, A.S.; DuBois, C. Development of a system for in vitro neck muscle force replication in whole cervical spine experiments. Spine 2001, 26, 2214-2219. [CrossRef] [PubMed]

45. Van Roy, P.; Caboor, D.; De Boelpaep, S.; Barbaix, E.; Clarys, J.P. Left-right asymmetries and other common anatomical variants of the first cervical vertebra. Man. Ther. 1997, 2, 24-36. [CrossRef] [PubMed]

46. Lantz, C.A.; Klein, G.; Chen, J.; Mannion, A.; Solinger, A.B.; Dvorak, J. A reassessment of normal cervical range of motion. Spine 2003, 28, 1249-1257. [CrossRef] [PubMed]

47. Villas, C.; Arriagada, C.; Zubieta, J.L. Preliminary CT study of C1-C2 rotational mobility in normal subjects. Eur. Spine J. 1999, 8, 223-228. [CrossRef] [PubMed]

48. Duan, S.Y.; Ye, F.; Kang, J.H. Three-dimensional CT study on normal anatomical features of atlanto-axial joints. Surg. Radiol. Anat. 2007, 29, 83-88. [CrossRef] [PubMed]

49. Buzzatti, L.; Provyn, S.; Van Roy, P.; Cattrysse, E. Atlanto-axial facet displacement during rotational high-velocity low-amplitude thrust: An in vitro 3D kinematic analysis. Man. Ther. 2015, 20, 783-789. [CrossRef] [PubMed]

50. Mönckeberg, J.; Tome, C.; Matias, A.; Alonso, A.; Vasquez, J.; Zubieta, J. CT scan study of atlantoaxial rotatory mobility in asymptomatic adult subjects: A basis for better understanding C1-C2 rotatory fixation and subluxation. Spine 2009, 34, 1392-1295. [CrossRef] [PubMed]

51. Yin, W.; Willard, F.; Dixon, T.; Bogduk, N. Ventral innervation of the lateral C1-C2 joint: An anatomical study. Pain Med. 2008, 9, 1022-1029. [CrossRef] [PubMed]

52. Eagle, W.W. Elongated styloid process: Report of 2 cases. Arch. Otolaryngol. 1937, 25, 584-587. [CrossRef]

53. Cattrysse, E.; Provyn, S.; Kool, P.; Clarys, J.P.; Van Roy, P. Morphology and kinematics of the atlanto-axial joints and their interaction during manual cervical rotation mobilization. Man. Ther. 2012, 16, 481-486. [CrossRef] [PubMed]

(C) 2016 by the authors; licensee MDPI, Basel, Switzerland. This article is an open access article distributed under the terms and conditions of the Creative Commons by Attribution (CC-BY) license (http:/ / creativecommons.org/licenses/by/4.0/). 